\title{
Effect of Laser Intensities on Additive Manufacturing Process - A Review
}

\author{
MR. D. DEV SINGH ${ }^{1}$, DR. A. RAJI REDDY ${ }^{2}$ \\ ${ }^{1}$ Research scholar, Department of Mechanical Engineering, JNTUH Hyderabad, India \\ ${ }^{I}$ Associate Professor, Department of Mechanical Engineering, CMR Institute of Technology /JNTUH \\ Hyderabad, India \\ ${ }^{2}$ Professor \& Director, Department of Mechanical Engineering, CMR Technical Campus /JNTUH Hyderabad, \\ India
}

\begin{abstract}
Design and manufacture of critical components has become an important process and still posing problems towards the desired quality. The critical components can be used in applications of navol, aerospace, biomedical and other applications. Additive manufacturing is an economical and simple process for manufacturing of such complex and intrinsic components. Rapid Prototyping or Additive Manufacturing is defined as conversion of $3 D$ CAD models into physical objects. Rapid Prototyping can be defined as used to generate non-structural and non-functional demo pieces or batch of one component for proof of concept. Whereas Additive Manufacturing is used as a real, scalable manufacturing process, to generate fully functional final components with high-tech materials for low batch, high-value manufacturing

The present research work is focused on manufacturing such of components using additive manufacturing (by selecting one of the proper manufacturing methods) with combination of alloys of Ti and Al for any applications. The CAD model of the components can be generated using any CAD package, Meshing by Hypermesh package and analyzed by ANSYS package. Performance and material characterization with variation of laser intensities will be conducted on additive manufacturing products. Finally the best composition of materials for additive manufacturing product and laser intensity will be studied, along with their defects and remedies.
\end{abstract}

Keywords: Additive manufacturing, Design and characterization, Rapid prototyping, Ti and Al alloy.

\subsection{Introduction:}

\section{Introduction}

Development in every field started, when a wheel manufactured in Iraq, which was happened Before Christ. After that the invention in late the 1903 by the Wright brothers', aircrafts have seen colossal improvements in their design, right from their engine to their outer structure and also from being manned airplane to an unmanned one. An Unmanned Air Vehicle (UAV), in simple terms is an aircraft without a human pilot on board. Its flight is controlled either automatically by computers in the vehicle or under the remote control of a pilot on the ground or in another vehicle. The typical launch and recovery method of an unmanned aircraft is the function of an automatic system or an external operator on the ground. Unmanned Air Vehicle are usually deployed for the military and special operation applications, such as policing and firefighting and nonmilitary security work such as surveillance of pipelines, aerial photography for mapping, surveying and disaster control etc., Unmanned Air Vehicle are usually preferred for missions that are too dull, or dangerous for manned aircrafts. The CAD model of those components can be generated using any CAD package, Meshing by Hypermesh package and analyzed by ANSYS package.

In this research work such components can be developed used for naval, aerospace, biomedical and other applications using the technology of Additive Manufacturing or Rapid Prototyping adopted for the fabrication.

\subsection{Rapid Prototyping:}

A Prototype is the first original model that has been developed. It is a model or preliminary version. The word Prototype is defined as a non in the Oxford Advanced Learner's Dictionary of Current English. In general covering all aspects of the word Prototype used in design can be defined as, "An approximation of a product / system or its components in some form for a definite purpose in its implementation.' Soft or virtual prototyping takes on a new meaning as more computer tools available- computer models can now be stressed, tested, analyzed and modified $\mathrm{s}$ if they were physical prototypes. 
The term Rapid Prototyping generally falls in the range of a physical prototype, usually accurate and can be implemented on a part level or at a product/system level. The term rapid prototyping (RP) refers to a class of technologies that can automatically construct physical models from Computer-Aided Design (CAD) data. The "three dimensional printers" allow designers to quickly create tangible prototypes of their designs, rather than just two-dimensional pictures. Such models have numerous uses. They make excellent visual aids for communicating ideas with co-workers or customers. In addition, prototypes can be used for design testing. For example, an aerospace engineer might mount a model of airfoil in a wind tunnel to measure lift and drag forces. Designers have always utilized prototypes and RP allows them to be made faster and less expensively. The key idea of rapid prototyping technology is based on decomposition of 3-D computer models into thin cross-sectional layers, followed by physically forming the layers and stacking them up "layer by layer."

"Additive Manufacturing(AM) /Rapid Prototyping(RP) can be defined as a group of techniques used to quickly fabricate a scale model of a part or assembly using three-dimensional computer aided design (CAD) data". Rapid Prototyping has also been referred to as solid free-form manufacturing; computer automated manufacturing, and layered manufacturing. Rapid Prototyping has obviously used as a vehicle for visualization.

\subsection{Methodology of Rapid Prototyping:}

The basic methods for all current rapid prototyping/ Additive Manufacturing techniques can be summarized as follows:

i. A CAD model is created using any CAD package, and then converted to STL format. The resolution can be set to minimize stair stepping

ii. The RP machine processes the STL file by creating sliced layers of the model.

iii. The first layer of the physical model is created by the Rapid Prototyping machine. The model is then lowered by the thickness of the next layer, and the process is repeated until completion of the model.

iv. The model can be taken out from the manufacturing bed or platform.

v. The supports are removed for support required components. Then the surface of the component model is finished and cleaned.

\subsubsection{The CAD Model:}

There are many different CAD packages capable of producing an STL file. For rapid prototyping it is essential that parts are complete and have continuity, i.e. the part to be built must be CAD, CAM, AE and other applications. CATIA, Solid works, I-DEAS represented as closed surfaces that unambiguously define an enclosed volume.

\subsubsection{The STL File:}

The standard file format for rapid prototyping is STL (Standard Triangulation Language), where the shape of the object is defined by a mesh of tiny triangles laid over the surfaces. The triangles must meet up exactly with each other, without gaps or overlaps, if the object is to be built successfully. The "slice files" which are used to build each individual layer are calculated from the STL file, and if there are any gaps between the triangles, then the edges of the slices are not properly defined.

STL is a standard output format from most CAD (computer-aided design) software, and the number of triangles used can be user-defined. Commonly the translation from the modeling format to STL leaves few flaws, and so the integrity of STL files is usually checked using special software before the files are used to build an object. Small errors can be corrected automatically, but big faults or ambiguities may need "repairing" by an engineer..

When creating an STL file from CAD, the resolution (also known as Tolerance, Chord Height or Facet Deviation) can be specified. Under-faceted STL files will affect the accuracy and may affect the appearance of the part. Over-faceted STL files will increase the time it takes to prepare the part, without improving the quality. There is therefore an optimum resolution for the STL file to give the best accuracy in the smallest file. The resolution is best set between $0.01 \mathrm{~mm}$ and $0.05 \mathrm{~mm}$ and the overall binary file size should not normally be more than 5 Mbytes.

\subsection{Classification of Rapid Prototyping Technologies:}

Rapid Prototyping Technologies are classified as:

Liquid Based RP Systems

- Stereolithography (SLA)

- Solid Ground Curing (SGC)

-Solid Object Ultraviolet-Laser Printer (SOUP)

-RP System for jewelry Industry 
- Rapid Freeze

-Two Laser Beams

- Microfabrication

\section{Solid Based RP Systems}

-Laminated Object Manufacturing (LOM)

- Fused Deposition Modeling (FDM)

-Kira Corporation's Paper Lamination Technology (PLT)

-3D Systems's Multi-Jet Modeling System (MJM)

-Ennex Corporation's Offset Fabbers

\section{Powder Based RP Systems}

-3D Systems's Selective Laser Sintering (SLS)

- Z Corporation s Three-Dimensional Printing (3DP)

-Optomec's Leser Engineered Net Shaping (LENS)

-Direct Shell Production Casting (DSPC)

- Multiphase Jet Solidification (MJS)

-Acram's Electron Beam Melting(EBM)

-Aeromet Corporation s Lasform Technology

- Precision Optical manufacturing’s Direct Metal Deposition(DMD).

\subsubsection{Selective Laser Sintering}

In SLS thermoplastic powder is spread by a roller over the surface of a build cylinder. The piston in the cylinder moves down one object layer thickness to accommodate the new layer of powder. The powder delivery system is similar in function to the build cylinder. Here, a piston moves upward incrementally to supply a measured quantity of powder for each layer. A laser beam is then traced over the surface of this tightly compacted powder to selectively melt and bond it to form a layer of the object. The process is repeated until the entire object is fabricated.

Since the objects are sintered they are porous. It may be necessary to infiltrate the part, especially metals, with another material to improve mechanical characteristics. The process is somewhat similar to stereolithography in principle as can be seen in Figure 1.1. In this case, however, a laser beam is traced over the surface of a tightly compacted powder made of thermoplastic material (A). The powder is spread by a roller (B) over the surface of a build cylinder (C). A piston (D) moves down one object layer thickness to accommodate the layer of powder. The powder supply system (E) is similar in function to the build cylinder. It also comprises a cylinder and piston. In this case the piston moves upward incrementally to supply powder for the process.

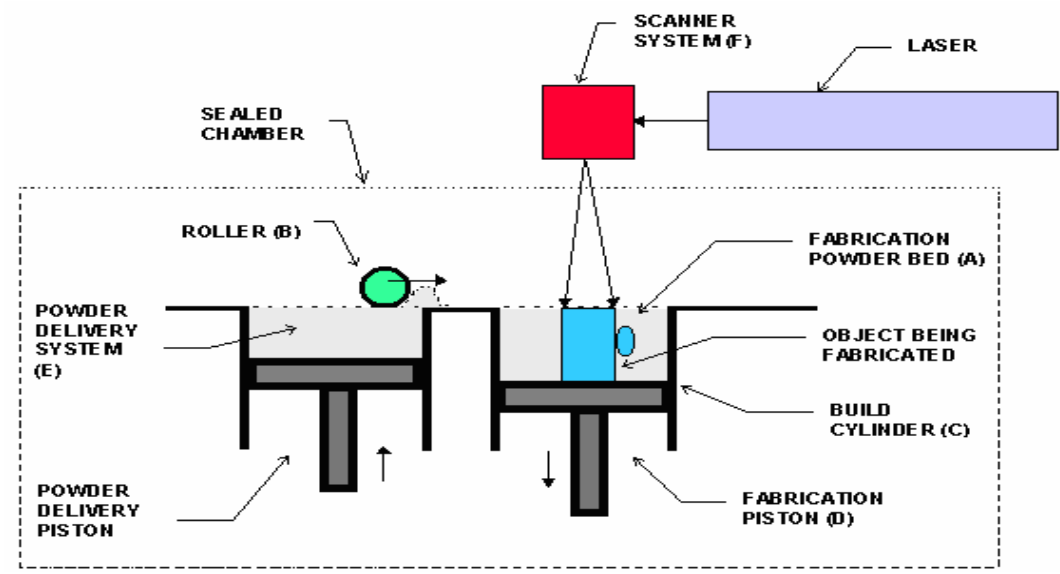

Figure 1.1 Selective Laser Sintering

\subsubsection{Electron Beam Melting (EBM)}

Electron Beam Melting and its working as shown in figure 1.2

1. The fabrication chamber is maintained at high vacuum and at high temperature.

2. A layer of metal powder is deposited on the fabrication bed/platform.

3. A focused electron beam is used to melt the powder particles in a small volume within the layer.

4. The electron beam is scanned to define a 2D slice of the object within the layer. 
5. The build table is lowered, and a new layer of dry powder is deposited on top of the previous layer.

6. After removal from the machine, the un melted powder is brushed off and recycled.

7. EBM process developed by Arcam AB, a Swedish Technology Development company in 1997 and was commercialized in the year 2001.

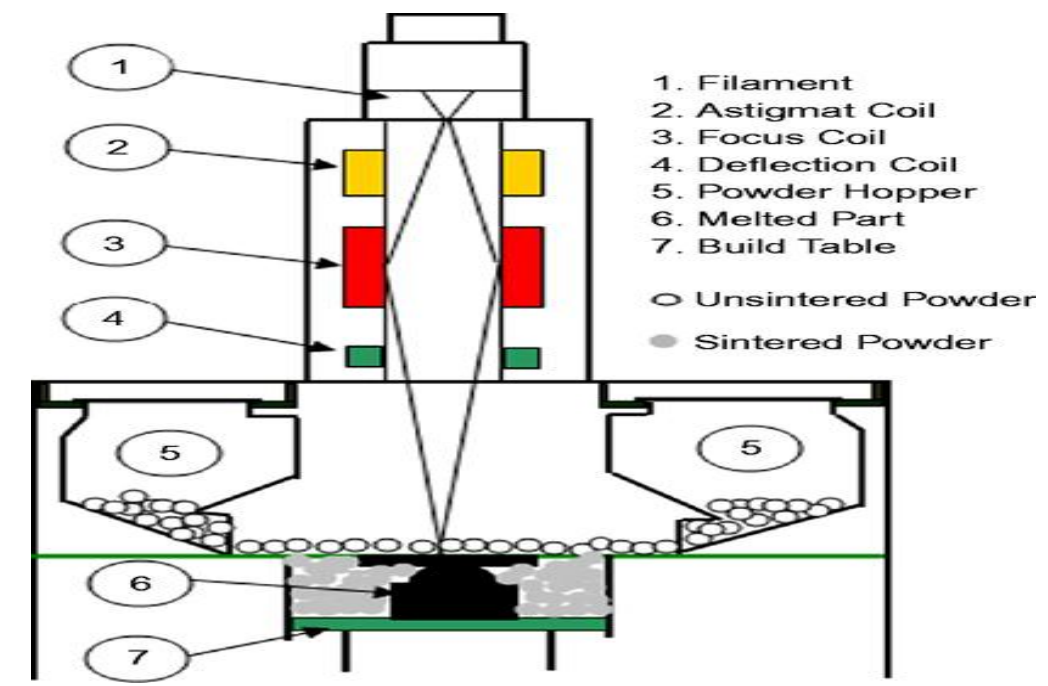

Figure 1.2 Detailed Electron Beam Melting

\section{Advantages:}

1. Rapid Prototyping system allowed the project manager for the completion of a project in three weeks from the year 1995.

2. The part designer can increase part complexity with little significant effect on lead time and cost.

3. Reducing of raw materials waste, waste disposal costs, material transport costs, inventory cost for raw material stock and finished parts.

4. Complex and accurate dimensional parts and products, made of different materials are obtained.

5. Customer can purchase the products which are available more closely at low cost.

\section{Applications:}

1. Applications in design, finishing processes.

2. Applications in engineering, Analysis and Planning.

3. Applications in Manufacturing and Tooling.

4. Applications in Aerospace industry, automotive industry, biomedical industry.

5. Applications in Jewelry industry, Coin industry, tableware industry.

\section{History}

Prototyping or model making is one of the important steps to finalize a product design. It helps in conceptualization of a design of an object. Before the start of full production a prototype is usually fabricated and tested. Manual prototyping by a skilled craftsman has been an age-old practice for many centuries. Second phase of prototyping started around 1970s, when a soft prototype modeled by 3D curves and surfaces could be stressed in virtual environment, simulated and tested with exact material and other properties. Third and in the latest trend of prototyping, i.e., Rapid Prototyping (RP) by layer-by-layer material deposition, started during early 1980s with the enormous growth in Computer Aided Design and Manufacturing (CAD/CAM) technologies when almost unambiguous solid models with knitted information of edges and surfaces could define a product and also manufacture it by using CNC machines. The historical development of RP and related technologies is presented in table 1 .

Table 1: Historical development of Rapid Prototyping and related technologies ${ }^{18}$

\begin{tabular}{|l|l|}
\hline Year of inception & Technology \\
\hline 1770 & Mechanization \\
\hline 1946 & First computer \\
\hline 1952 & First Numerical Control (NC) machine tool \\
\hline 1960 & First commercial laser \\
\hline 1961 & First commercial Robot \\
\hline 1963 & First interactive graphics system (early version of Computer Aided Design) \\
\hline 1988 & First commercial Rapid Prototyping system \\
\hline
\end{tabular}


Rapid Prototyping (RP) is the collective name for a set of different technologies and processes used to manufacture models directly from a three-dimensional (3D) Computer Aided Design (CAD) model by constructively building them in layers. RP technologies have gained diversity, complexity, sophistication and popularity since their introduction in the late 1980's. The use of RP in product design and development has had a significantly positive effect and has been shown to reduce development costs by 40 to $70 \%$ and the time to market by as much as $90 \%$. RP parts have been used in a range of areas such as design visualization, pattern building, assembly verification and functional testing.

"Plating on plastics" is a term used to depict the embellishing or useful application of metal onto plastic substrates utilizing the procedure of electroplating in 2007 by Z Zhou et al [1] Before plastics can be electroplated, they initially need to be metalized. Chandrasekhar. U, Venkatesh. K, Elangovan. K, Rangaswamy, et al. 2011[2] Integrated use of rapid prototyping and metal plating techniques for development of Micro Air Vehicles. This paper describes the collegial application of rapid prototyping and metal plating technologies for the development of MAV. Mithun V Kulkarni et al.2012 [3] In the present research, ABS (acrylonitrilebutadiene styrene), plastic is electroplated with copper $(\mathrm{Cu})$ and Nickel $(\mathrm{Ni})$ electrolytic solutions. The coating thickness of $\mathrm{Cu}$ and $\mathrm{Ni}$ layer approximates to $5 \mu \mathrm{m}$ and $35 \mu \mathrm{m}$ respectively. These coated samples are subjected to FEM analysis to make a note of increase or decrease in the mechanical strength. Wu H., Sun, D., Zhou, Z., et al. 2004[4] Micro air vehicle: Configuration, analysis, fabrication and test. This paper speaks of two electrically powered MAV with wingspans of 380 and $360 \mathrm{~mm}$.

Paul Marks.et al .2011 [5] 3D printing has been extensively developed since its origins as an expensive prototyping tool over two decades ago. It uses laser-assisted machines to fabricate plastic or metal objects. Jamieson et al [6] The solid models from various resources are converted into STL format files or other format files, which mostly come along with the FDM machines. Slicing procedures are implemented before the deposition. A lot of research is focused on slicing algorithms and attempting to reduce the stair-case effects and anisotropy of the final physical models. Karalekas \& Antoniou,et al 2004[7] Composite rapid prototyping, overcoming the drawback of poor mechanical properties. In this paper the authors investigate the effect of reinforcing, on the rapid prototypes fabricated from stereolithography and vacuum curing processes.

John K Borchardt et al. 2004[8] Unmanned aerial vehicles spur composite use. Keeping flight time of the UAV's in mind, the UAV's are making use of light but durable materials. Hague, et al. 2004[9] Material and design considerations for rapid manufacturing. This paper makes the assumption that the RP machines have evolved to as a reliable manufacturing systems and problems like accuracy, surface finish, repeatability which are profound in today's RP systems eliminated. M.ShemelyaJoel et al 2015 [10] Material extrusion 3D printing (ME3DP), based on fused deposition modeling (FDM) technology is currently the most widely available 3D printing platform. The work presented in this paper analyzes the effect of physical property-altering additives to acrylonitrile butadiene styrene (ABS) on mechanical property anisotropy. Chungshan N.Road 2000[11] In the FDM processing, layer thickness, road width and speed are three significant parameters influencing the form and surfaces quality of prototypes. H. Li, G. Taylor et al 2015[12] Modeling and characterization of fused deposition modeling tooling for vacuum assisted resin transfer molding process; Jing Yi et al 2015 [13] Preparation and characterization of large diameter pitch based carbon fiber/ABS resin composites with high thermal conductivities.

Nikzad Mostafa et al 2009 [14] A Study of Melt Flow Analysis of an ABS-Iron Composite in Fused Deposition Modelling Process; Vijay Petley, Chandrasekhar et al 2015 [15] Microstructure and mechanical characteristics of $\mathrm{Ni}-\mathrm{Cr}$ thin films. Ni-Cr alloy thin films have been deposited using magnetron co-sputtering technique at room temperature. Prashant K. Jain, et al 2006 [16] Advances in materials for powder based rapid prototyping.

\section{Current Reviews}

Huy Nguyen and Michael Vai 2010 [22] Rapid Prototyping Technology- Lincoln laboratory journal, Rapid Advanced Processor In Development (rapid) is a prototyping technology that accelerates the development of state-of-the-art processor systems, particularly those involving custom boards and firmware.

Prof. D.V. Mahindra \& Prof. Priyanka Mahendru 2013[23] Review of Rapid Prototyping-Technology for the Future. The term "Rapid Prototyping" (RP) refers to a class of technologies that can automatically construct physical models from computer-Aided Design (CAD) data

Jie Liu, Biao Zhang, Chunze Yan, Yusheng Shi, 2010 [24] The effect of processing parameters on Characteristics of selective laser sintering dental glass-ceramic powder. Purpose - The purpose of this paper is to report a study about the rapid prototyping method of dental glass-ceramic restoration. Dental glass-ceramic restoration materials have excellent physical and chemical, mechanical, aesthetic and biocompatibility characteristics. This study will provide a theoretical and technical basis for dental glass-ceramic restorations of SLS. 
Prof. Deepa yagnik 2014 [25] Presented the paper on Fused Deposition Modeling - A Rapid Prototyping technique for Product Cycle Time Reduction cost effectively in Aerospace Applications. This Paper Focus on Fused Deposition Modeling (FDM) Technique, Use of FDM for Aerospace applications with a case study of Aernautics Engineering depicting FDM as sole way for product cycle time reduction cost effectively.

Uichung Cho, Kristin L. Wood, Richard H. Crawford, 1998 [26]"Online functional testing with Rapid Prototypes: a novel empirical similarity method". Functional testing with rapid prototypes is confined to certain areas due to a number of issues. The lack of are liable similarity method that can solve distorted similarity problems; limited material choices; range of prototype sizes; and distinct material structures between prototypes and actual products.

M.M. Selamat 2016 [27] Innovative Powder delivery system for the Selective Laser Melting (SLM).The purpose of this project is to develop an innovative powder delivery system for the selective laser melting (SLM). SLM is driven by the need to process near full density objects with mechanical properties comparable to those of bulk materials. SLM is more difficult to control compared to the SLS due to the large energy input of the laser beam and the complete melting of particles problems such as balling, residual stresses and deformation tend to be occurred. The stainless steel powder will be used with the size of $0.002 \mathrm{~mm}$ (20microm - 50microm). D.J. Thomas, Z. Tehrani, B. Redfearn2015 [28] 3-D printed composite microfluidic pump for wearable biomedical applications. An integrated wearable 3-D printable micro fluidic pump was developed, which uses a novel actuation process. Fused deposition manufacture 3-D printing was used as a means to accurately produce this device. Biofluids have been driven through the device by actuating a composite polydimethylsiloxane diaphragm actuated polymeric microstructure diaphragm membrane using electromagnetic force.

Seshadev Sahoo, Kevin Chou 2015[29] Phase-field simulation of microstructure evolution of Ti-6Al$4 \mathrm{~V}$ in electron beam additive manufacturing process. Electron beam additive manufacturing (EBAM) is a relatively new technology to produce metallic parts in a layer by layer fashion by melting and fusing the metallic powders. Ti-6Al- $4 \mathrm{~V}$ is one of the most used industrial alloys used for aerospace and biomedical applications. In this study, a phase field model is developed for microstructure evolution of Ti-6Al-4V powder in EBAM process. Wessel W.Wits et al 2015 [30] Single scan vector prediction in selective laser melting. In selective laser melting (SLM) products are built by melting layers of metal powder successively. Optimal process parameters are usually obtained by scanning single vectors and subsequently determining which settings lead to a good compromise between product density and build speed. This paper proposes a model that describes the effects occurring when scanning single vectors. Energy absorption and heat conduction are modeled to determine the temperature distribution and melt pool characteristics for different laser powers, scan speeds and layer thicknesses.

D. D. Gu, W. Meiners, et al 2012 [31] Laser additive manufacturing of metallic components: materials, processes and mechanisms. Additive manufacturing implies layer by layer shaping and consolidation of powder feedstock to arbitrary configurations, normally using a computer controlled laser. The current development focus of AM is to produce complex shaped functional metallic components, including metals, alloys and metal matrix composites (MMCs), to meet demanding requirements from aerospace, defence, automotive and biomedical industries The present review initially defines LS/LM/LMD processes and operative consolidation mechanisms for metallic components. The overall objective is to establish a relationship between material, process, and metallurgical mechanism for laser based AM of metallic components.

Yas Khalil et al 2016 [32] Influence of energy density on flexural properties of laser-sintered UHMWPE. Ultra High Molecular Weight Polyethylene (UHMWPE) is a semi-crystalline polymer that has remarkable properties of high mechanical properties, excellent wear resistance, low friction and chemical resistance, and it is found in many applications such sporting goods, medical artificial joints, bullet proof jackets and amours, ropes and fishing lines This paper reports attempts to laser-sinter UHMWPE and assesses the effects of laser energy density on the flexural properties of the sintered parts.

\section{Conclusions}

From the above journals the following conclusions are observed.

1. The CAD solid models of the objects can be converted into STL file format, which slice the models.

2. Development of 3D laser printer for the fabrication of plastics and metallic components.

3. 3D printing using ABS materials based on FDM with various speeds for getting good surface finished components.

4. Development of electroplating of plastics and ABS with cupper and nickel for micro air vehicles and their analysis was studied.

5. Production of high thermal conductivity of carbon fiber/ABS resin composite.

6. A study of melt flow analysis of an ABS-iron composite in FDM process. 
7. The development of RP products in less time using CAD computer systems.

8. The effect of the Process parameters on dental glass-ceramics powder by Selective Laser Sintering.

9. Fused Deposition Modeling - A Rapid Prototyping technique for Product Cycle Time Reduction cost effectively in Aerospace Applications.

10. Online functional testing with rapid prototypes is novel empirical similarity method, to know the size and material structure.

11. Powder delivery system for the Selective Laser Melting for the production of stainless steel components.

12. Development of micro fluid pumps for biomedical applications.

13. An explanation of Microstructure evolution of $\mathrm{Ti}-6 \mathrm{Al}-4 \mathrm{~V}$ in electron beam additive manufacturing process for aerospace and biomedical applications.

14. Single scan vector prediction in selective laser melting by varying process parameters.

15. The establishment of relationship between material, process, and metallurgical mechanism for laser based dative manufacturing of metallic components.

16. The reports attempts to laser-sinter UHMWPE and assesses the effects of laser energy density on the flexural properties of the sintered parts.

\section{References}

[1] Z Zhou, D Li, J Zeng and Z Zhang, Rapid fabrication of metal-coated composite stereolithography parts, Proceedings of the Institution of Mechanical Engineers, Part B: Journal of Engineering Manufacture (2007), Vol. 221, pp.1431-1440.

[2] Chandrasekhar. U, Venkatesh. K, Elangovan. K, Rangaswamy. T, Integrated Use of Rapid Prototyping and Metal Plating Techniques For Development of Micro Air Vehicles, International Journal of Engineering Science and Technology, 3(1), 2011, pp:188-193.

[3] Methuen V. Kulkarni., K. Elangovan., and K. Hemachandra Reddy. (2012) 'Development Of Electroplating Setup For Plating ABS Plastics', i-manager's Journal on Mechanical Engineering, Vol. 2 No. 3, pp. 52-57.

[4] Wu H., Sun, D., Zhou, Z., 2004, "Micro Air Vehicle: Configuration, Analysis, Fabrication and Test", IEEE/ASME Transactions on Mechatronics, vol. 9, no. 1, p. 108-117.

[5] Paul Marks., 2011, 3D printing has been extensively developed the World's First Printed Plane”. New Scientist, August 2011.

[6] Jamieson, the solid models from various resources are converted into STL format files or other format files, which mostly come along with the FDM machines. Slicing procedures are implemented before the deposition.

[7] Karalekas D and Antonioua K, 2004, "Composite rapid prototyping: overcoming the drawback of poor mechanical properties" Journal of Materials Processing Technology, Vol 153-154, pp.526-530.

[8] John K Borchardt Unmanned aerial vehicles spur composites use Reinforced Plastics, Volume 48, Issue 4, April 2004, Pages 28-31

[9] Hague R, Mansour S, and Saleh N, 2004, "Material and design considerations for rapid manufacturing", International Journal of Production Research, 42(22), 4691-4708.

[10] Angel R. Torrado, Corey M. Shemelya, Joel D. English, Yirong Lin, Ryan B. Wicker, David A. Roberson, Characterizing the effect of additives to ABS on the mechanical property anisotropy of specimens fabricated by material extrusion 3D printing Additive Manufacturing, Volume 6, April 2015, Pages 16-29

[11] Chungshan N.Road, Department of Materials Engineering, Tatung University, 40, 3rd Section, Taipei 10451, Taiwan, ROC Received 25 November 1997,Revised 4 November 1999, Accepted 28 January 2000, Available online 6 October 2000

[12] H. Li, G. Taylor, V. Bheemreddy, O. Iyibilgin, M. Leu, K. Chandrashekhara, Modeling and characterization of fused deposition modeling tooling for vacuum assisted resin transfer molding process Additive Manufacturing, Available online 8 April 2015.

[13] Jing Yi, Guan-ming Yuan, Xuan-ke Li, Hong-da Du, Zhi-jun Dong, Bao-liu Li, Jian-feng Lin Preparation and characterization of large diameter pitchbased carbon fiber/ABS resin composites with high thermal conductivities Carbon, Volume 86, May 2015, Page 373.

[14] Nikzad Mostafa, Hasan Masood Syed, Sbarski Igor, Groth Andrew, A Study of Melt Flow Analysis of an ABSIron Composite in Fused Deposition Modelling Process Tsinghua Science \& Technology, Volume 14, Supplement 1, June 2009, Pages 29-37.

[15] Vijay Petley, S. Sathishkumar, K.H. Thulasi Raman, G.Mohan Rao, U. Chandrasekhar Microstructural and mechanical characteristics of Ni-Cr thin films Materials Research Bulletin, Volume 66, June 2015, Pages 59-64.

[16] LAPA Digital Technology Seminar and Workshop 1: Mai 10 \& 11 200/ Version1.1 by Prof. H.Gugger, Assistant R.Loveridge

[17] RAPID PROTOTYPING (Laser-based and Other Technologies) by Patri K. Venuvinod and Wei yin Ma, City University of Hong Kong

[18] RAPID PROTOTYPING, Principles and Applications; Second edition by CHUA C.K, LEONG K.F and LIM C.S

[19] Phase-field simulation of microstructure evolution of Ti-6Al-4V in electron beamadditive manufacturing process, A Full length article by Seshadev Sahoo and Kevin Chou, Department of Mechanical Engineering, The University of Alabama,Tuscaloosa, AL 35487, USA 
[20] Laser additive manufacturing of metallic components: materials, processes and Mechanisms; A Full length article by D. D. Gu, W. Meiners, K. Wissenbach andR. Poprawe

[21] advances in materials for powder based rapid prototyping advances in materials for powder based rapid prototyping, In Proceeding of International Conference on Recent Anvances in Materials and Processing Dec. 15-16, 2006, PSGtech. Coimbatore, INDIA, Prashant K. Jain, K. Senthil kumaran, Pulak M. Pandey, P. V. M. Rao

[22] Rapid Prototyping Technology- Volume 18, Number 2, 2010 lincoln laboratory journal, by Huy nguyen and Michael Vai.

[23] Review of Rapid Prototyping-Technology for the Future. Global Journal of Computer Science and Technology Graphics \& Vision Volume 13 Issue 4 Version 1.0 Year 2013 Type: Double Blind Peer Reviewed International Research Journal Publisher: Global Journals Inc. (USA) Online ISSN: 0975-4172 \& Print ISSN: 0975-4350 br Prof. D.V. Mahindru \& Prof. Priyanka Mahendru.

[24] "The effect of processing parameters on characteristics of selective laser sintering dental glass-ceramic powder", Rapid Prototyping Journal, Vol. 16 Iss: 2 pp. 138 - 145 by ]. Jie Liu, Biao Zhang, Chunze Yan, Yusheng Shi.

[25] Presented the paper on Fused Deposition Modeling - A Rapid Prototyping technique for Product Cycle Time Reduction cost effectively in Aerospace Applications in International Conference on Advances in Engineering \& Technology - 2014 (ICAET-2014) by Prof. Deepa yagnik.

[26] "Online functional testing with rapid prototypes: a novel empirical similarity method", Rapid Prototyping Journal, Vol. 4 Iss: 3 pp. 128 - 138 by Uichung Cho, Kristin L. Wood, Richard H. Crawford.

[27] Innovative Powder delivery system for the Selective Laser Melting (SLM) by M.M. Selamat.

[28] 3-D printed composite microfluidic pump for wearable biomedical applications; Article history published in Elsvier journal: Received 12 June 2015, Received in revised form 14 November 2015, Accepted 14 December 2015, Available online 12 January 2016 by D.J. Thomas, Z. Tehrani, B. Redfearn.

[29] Phase-field simulation of microstructure evolution of Ti-6Al-4V in electron beam additive manufacturing process; Article history published in Elsvier journal: Received 28 April 2015, Received in revised form 19 November 2015, Accepted 16 December 2015, Available online 28 December 2015. Seshadev Sahoo, Kevin Chou .

[30] Single scan vector prediction in selective laser melting; Article history published in Elsvier journal: Received 27 April 2015, Received in revised form 26 August 2015, Accepted 14 December 2015, Available online 19 December 2015 by Wessel W. Wits, Rutger Bruins, Lennard Terpstra, Rob A. Huls, H.J.M. Geijselaers.

[31] Laser additive manufacturing of metallic components: materials, processes and mechanisms; International Materials Reviews 2012 VOL 57 NO 3 133; Institute of Materials, Minerals and Mining and ASM International Published by Maney for the Institute and ASM International DOI 10.1179/1743280411Y.0000000014 by ] D. D. Gu, W. Meiners, K. Wissenbach and R. Poprawe.

[32] Influence of energy density on flexural properties of laser-sintered UHMWPE; Article history published in Elsvier journal: Received 25 November 2015 Received in revised form 4 February 2016 Accepted 11 March 2016 Available online 14 March 2016 by Yas Khalil, Adam Kowalski, Neil Hopkinson 